\title{
Long-Term Monitoring of Flicker and Some Other Parameters of Voltage Quality
}

\author{
Petr Krejci, Pavel Santarius, Radomir Gono, Zdenek Brunclik
}

\begin{abstract}
In 1997 cooperation began between the Faculty of Electrical Engineering and Computer Science and the power company CEZ on a joint project that involved monitoring selected voltage quality parameters. Over the course of several years measurements were carried out at 59 points of the distribution system at a low voltage (LV) level and their power supply nodes at medium voltage (MV) and high voltage (HV) levels, which constituted more than 100 measured points. The measurements continued until 2012 (with a one-year break in 2009) and with a total scope of five cycles of three-year measurements. The last phase of the measurements was focused, inter alia, on the evaluation of 15th and 21st voltage harmonics. From 2013, the cooperation focused again on monitoring flicker in localities with the occurrence of elevated levels of this voltage quality parameter. At these sites, the monitoring of flicker was carried out for two weeks in spring and autumn for a period of three years. The basis for evaluating the quality parameters is the standard EN 50160. In addition the results of annual continual monitoring for one selected locality on MV level will be presented in the paper. In addition the possibility of utilization of intelligent electrometers for monitoring of some quality parameters will be referred in the paper.
\end{abstract}

Index Terms - flicker, unbalance, voltage harmonics, voltage quality.

\section{COMPREHENSIVE LONG-TERM MONITORING OF SOME PARAMETERS OF THE VOLTAGE QUALITY IN THE REGIONAL POWER ENGINEERING COMPANY}

As already mentioned, in 1997 cooperation began between the Faculty of Electrical Engineering and Computer Science and the power company CEZ on a joint project that involved monitoring selected voltage quality parameters. Among the main parameters to be monitored were selected harmonic voltages, flicker and voltage unbalance. Given the large number of measurement points, the measurements were divided into six partial stages (the whole range that was measured is shown in Fig. 1), in order to complete the entire measuring cycle within

This research was partially supported by the SGS grant from VSB Technical University of Ostrava (No. SP2016/95 and No. SP2016/146).

Petr Krejci, Pavel Santarius, Radomir Gono

- Faculty of Electrical Engineering and Computer Science

- VSB - Technical University of Ostrava, Ostrava, Czech Republic three years. After that period the measurements were repeated, and because they involved five three-year measurement cycles, the monitoring of these quality parameters lasted for 15 years. According to the requirements of the EN 50160 standard [1], the measurement of the voltage quality parameters was carried out for one week, with a measurement interval of 10 minutes. A diagram of the connection of the measuring points is shown in Fig. 2.

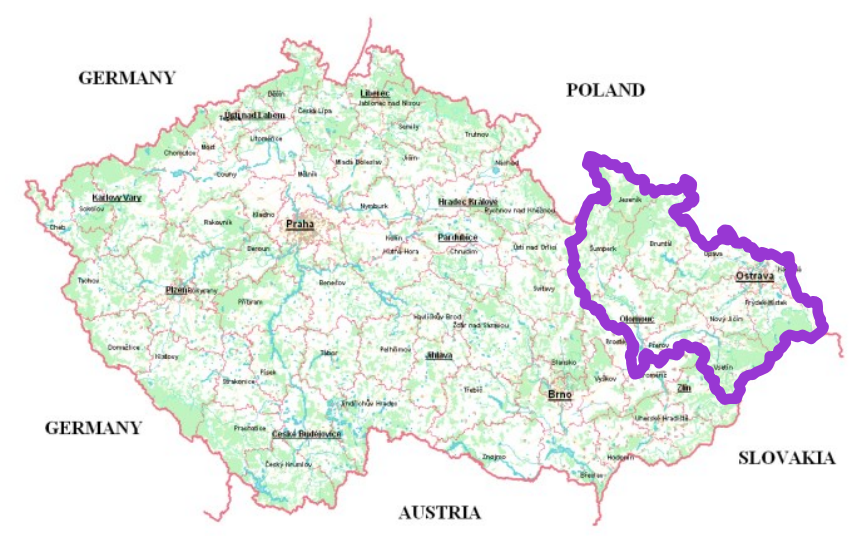

Fig. 1. Locality of Measurement

At single feeder points the measured data was evaluated in all phases and on all voltage levels:

- $\quad$ Selected voltage harmonics (3rd, 5th, 7th, 9th, 11th)

- $\quad$ Flicker

- $\quad$ Unbalance $(\mathrm{N})$
- petr.krejci@vsb.cz, pavel.santarius@vsb.cz, radomir.gono@vsb,cz

Zdenek Brunclik

- CEZ Distribuce, a.s.,

- Czech Power Company (CEZ), Ostrava, Czech Republic

- zdenek.brunclik@cez.cz 


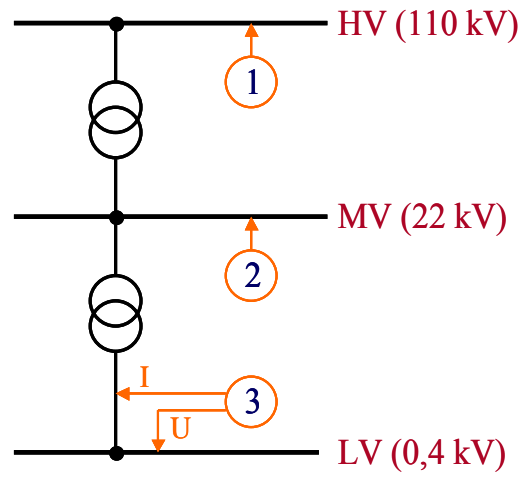

Fig. 2. Ideal connection diagram of measuring points

The results of this long-term measurement have been published continuously, e.g. [2]. This paper summarises the results and particularly the trends in the changes in the voltage quality parameters over the monitoring period of 15 years.

\section{CONCLUSIONS - THE TRENDS OF CHANGES}

Continuous results of the measurements have already been published several times, e.g. [2]. In the tables below the changes in the selected voltage quality parameters (selected harmonics, flicker and unbalance) in the LV, MV and HV network during the five monitoring cycles are summarised. An example of an evaluation of selected voltage quality parameters (fifth harmonic, flicker and unbalance) in the LV networks is shown in Fig. 3.

TABLE I. TRENDS OF CHANGES IN THE SELECTED VOLTAGE QUALITY PARAMETERS IN THE LV NETWORKS

\begin{tabular}{|l|l|l|l|l|}
\hline & LV II.-I. & LV III.-II. & LV IV.-III. & LV V.-IV. \\
\hline U_03 (\%) & 0.056 & -0.016 & -0.004 & 0.00 \\
\hline U_05 (\%) & 0.157 & 0.204 & -0.334 & -0.11 \\
\hline U_07 (\%) & 0.095 & 0.204 & -0.017 & -0.04 \\
\hline U_09 (\%) & 0.006 & 0.026 & 0.010 & 0.02 \\
\hline U_11 (\%) & 0.015 & 0.075 & 0.024 & 0.05 \\
\hline P $_{\text {st }}(-)$ & 0.157 & -0.034 & 0.008 & 0.05 \\
\hline P $_{\text {It }}(-)$ & 0.118 & -0.005 & -0.022 & -0.05 \\
\hline N (\%) & 0.088 & 0.043 & -0.066 & -0.02 \\
\hline
\end{tabular}

TABLE II. TRENDS OF CHANGES IN THE SELECTED VOLTAGE QUALITY PARAMETERS IN THE MV NETWORKS

\begin{tabular}{|c|c|c|c|c|}
\hline & MV II.-I. & MV III-II. & MV IV-III. & MV V.-IV. \\
\hline U_03 (\%) & 0.056 & -0.026 & -0.019 & -0.02 \\
\hline U_05 (\%) & 0.335 & 0.181 & -0.303 & -0.14 \\
\hline U_07 (\%) & 0.111 & 0.193 & -0.022 & -0.09 \\
\hline U_09 (\%) & -0.018 & -0.009 & -0.006 & 0.00 \\
\hline U_11 (\%) & 0.016 & 0.036 & 0.021 & -0.01 \\
\hline $\mathbf{P}_{\text {st }}(-)$ & 0.135 & -0.093 & 0.048 & -0.06 \\
\hline$P_{\text {It }}(-)$ & 0.077 & -0.079 & 0.022 & -0.07 \\
\hline $\mathbf{N}(\%)$ & 0.135 & -0.052 & -0.058 & -0.01 \\
\hline
\end{tabular}

TABLE III. TRENDS OF CHANGES IN THE SELECTED VOLTAGE QUALITY PARAMETERS IN THE HV NETWORKS

\begin{tabular}{|l|l|l|l|l|}
\hline & HV II.-I. & HV III-II. & HV IV-III. & HV V-IV. \\
\hline U_03 (\%) & 0.183 & 0.089 & -0.067 & -0.045 \\
\hline U_05 (\%) & 0.065 & 0.106 & -0.082 & -0.057 \\
\hline U_07 (\%) & 0.040 & 0.073 & -0.004 & 0.013 \\
\hline U_09 (\%) & -0.050 & -0.012 & -0.002 & -0.012 \\
\hline U_11 (\%) & -0.001 & 0.001 & 0.022 & -0.021 \\
\hline P st (-) $_{\text {P }}$ & 0.113 & -0.024 & 0.050 & -0.091 \\
\hline $\mathbf{P}_{\text {lt }}(-)$ & 0.131 & -0.080 & 0.050 & -0.103 \\
\hline N (\%) & -0.017 & 0.169 & -0.176 & 0.031 \\
\hline
\end{tabular}

The most important conclusions:

a) as regards harmonics, the results are relatively positive; the values of individual harmonic components are significantly below the values of compatible levels and the fifth harmonic was the most considerable at all voltage levels. The extreme values were only found at one point in the LV network, where it exceeded the third harmonic in $1999(10.7 \%)$ and in $2002(12.6 \%)$ and the ninth harmonic in $2002(2.1 \%)$. The probable reason for this was resonance in the LV network;

b) as for unbalance, the changes are also quite small. A small exceeding was only found at three points in the MV network;

c) as for flicker, the situation was worse. Exceeding the compatibility level was found at many measuring points and on all voltage levels;

d) the trends of changes in the selected voltage quality parameters during the years 1997 to 2012 do not show extreme swings or a long-term increase in the selected voltage quality parameters.

\section{MEASURING AND EVALUATION OF $15^{\mathrm{TH}}$ AND $21^{\mathrm{ST}}$ HARMONICS}

In the last monitoring cycle $(2010-2012)$ the $15^{\text {th }}$ and $21^{\text {st }}$ voltage harmonics in the LV distribution network were measured and evaluated. The measuring and evaluation were performed by analysers with a measuring uncertainty of $0.1 \%$ of the first harmonic.

The compatibility level of $0.5 \%$ was not exceeded at any measurement point. The results of the evaluation of the $15^{\text {th }}$ and $21^{\text {st }}$ voltage harmonics in the LV distribution network are shown in Fig. 4. 


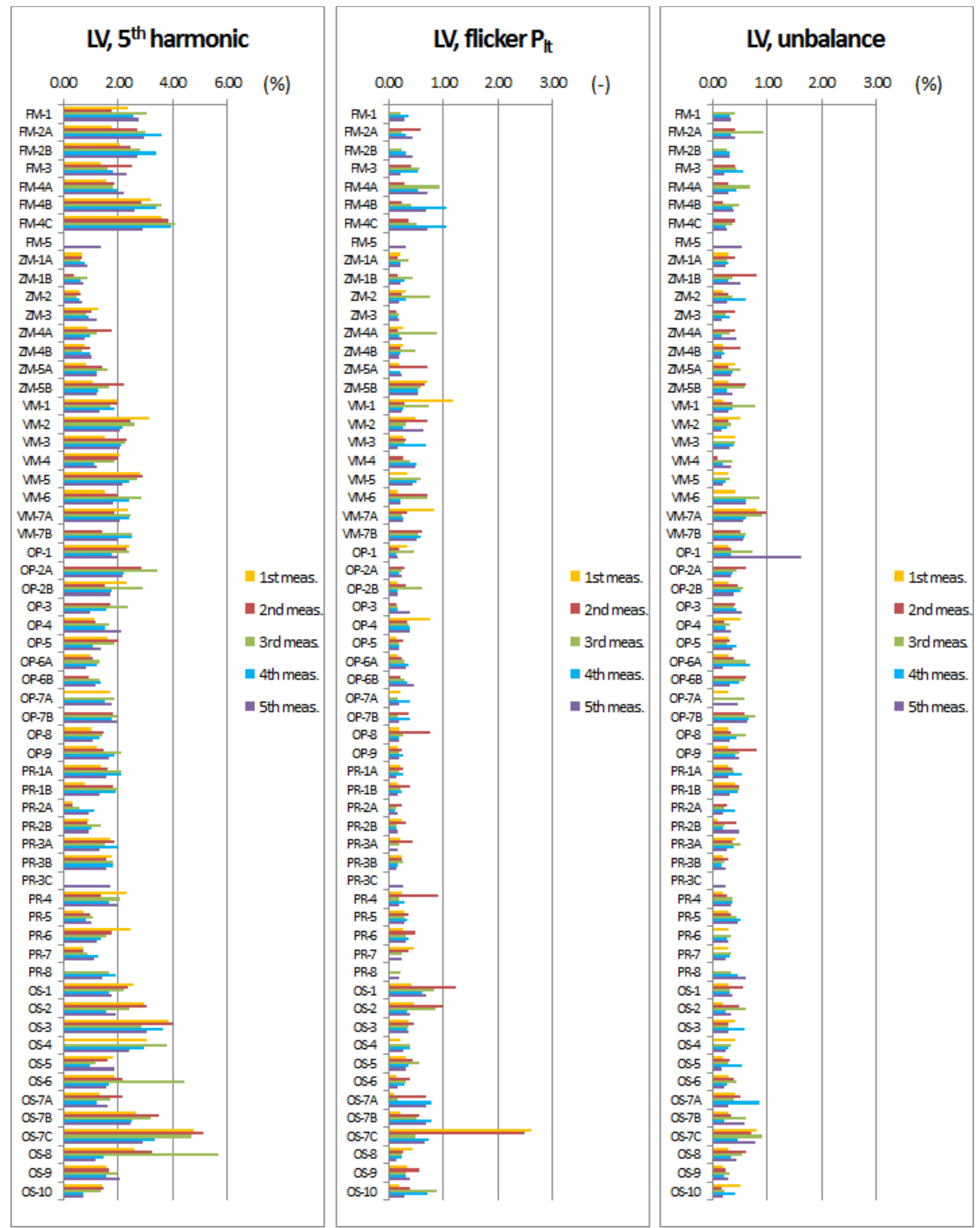

Fig. 3. Example of evaluation of selected voltage quality parameters (fifth harmonic, flicker and unbalance) in the LV networks 


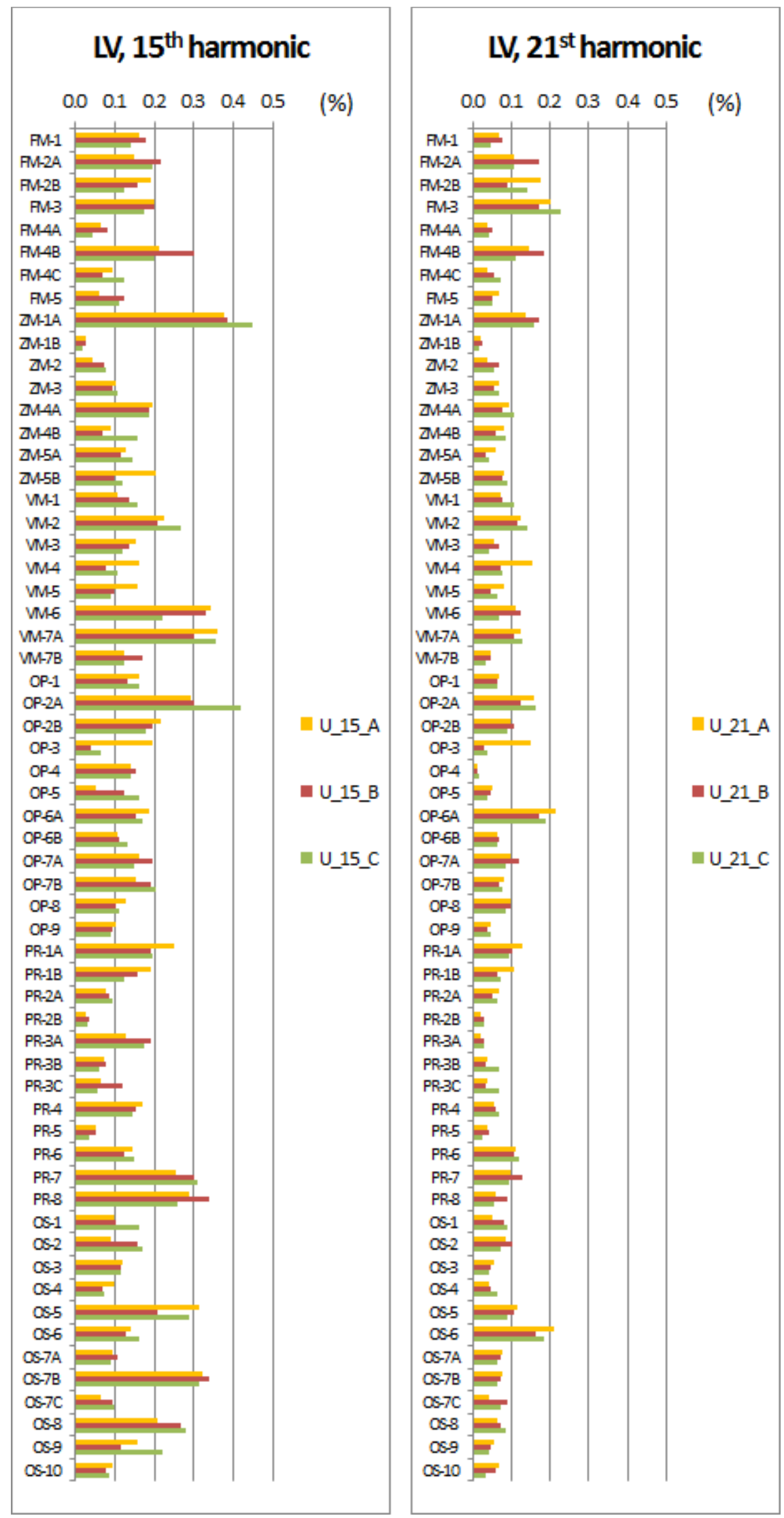

Fig. 4. The results of the measuring and evaluation of the $15^{\text {th }}$ and $21^{\text {st }}$ voltage harmonics in the LV distribution network 
IV. LONG-TERM MEASURING OF FLICKER

In 2014 we started the long-term monitoring of flicker [3] at the feeding points at which a problem with compatibility limit violation of flicker was detected. The measuring was done during a two-week period in spring and in autumn. In the figures below examples of the evaluation of $\mathrm{P}_{\mathrm{st}}$ and $\mathrm{P}_{\mathrm{lt}}$ in the spring (Fig. 5) and autumn of 2014 (Fig. 6) are shown.

From the present results of the flicker monitoring it is possible to state that at some feeding points the values of $\mathrm{P}_{\mathrm{lt}}$ were more than 1 . The greatest value was 1.7 .
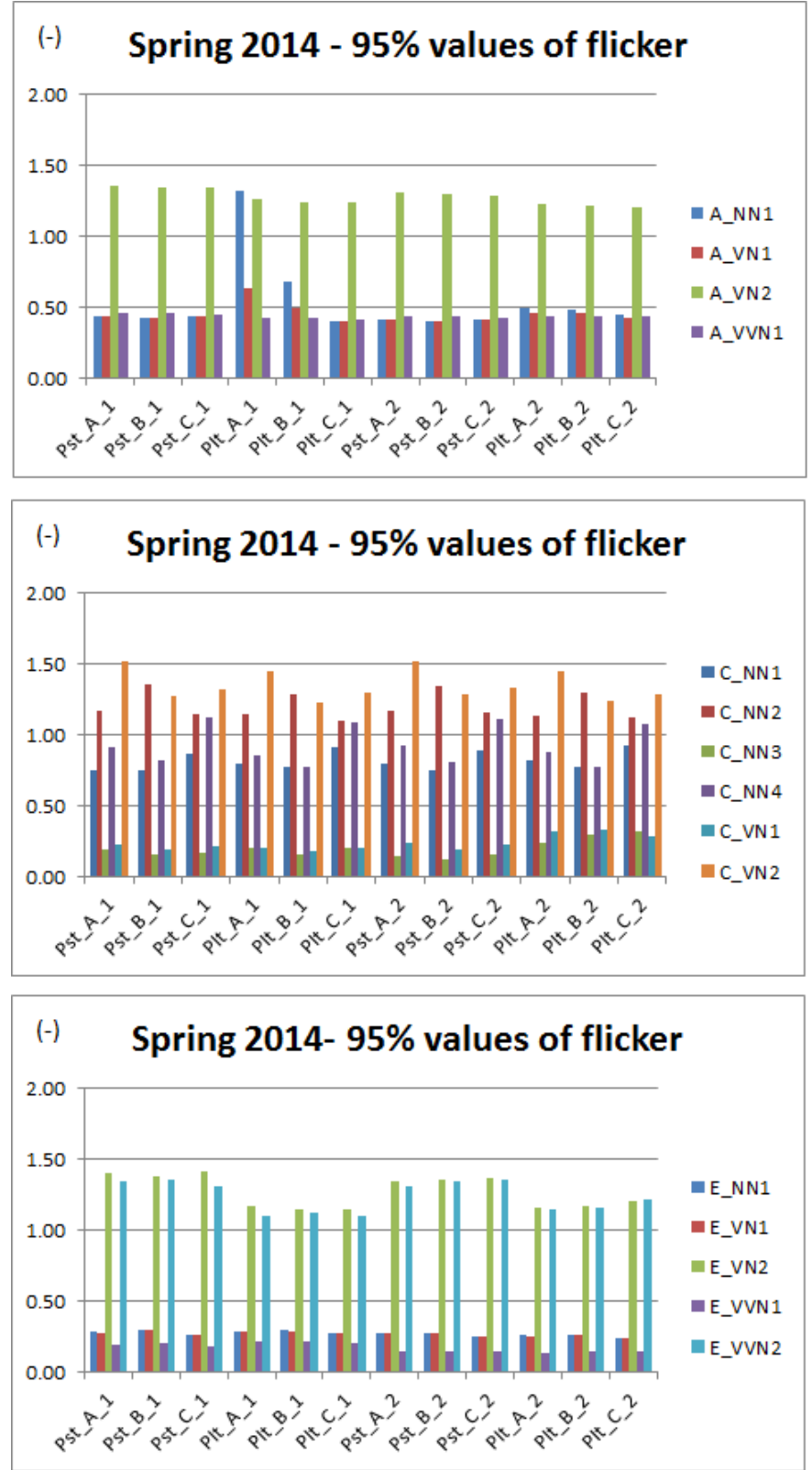

Fig. 5. The results of the measuring of flicker - Spring 2014
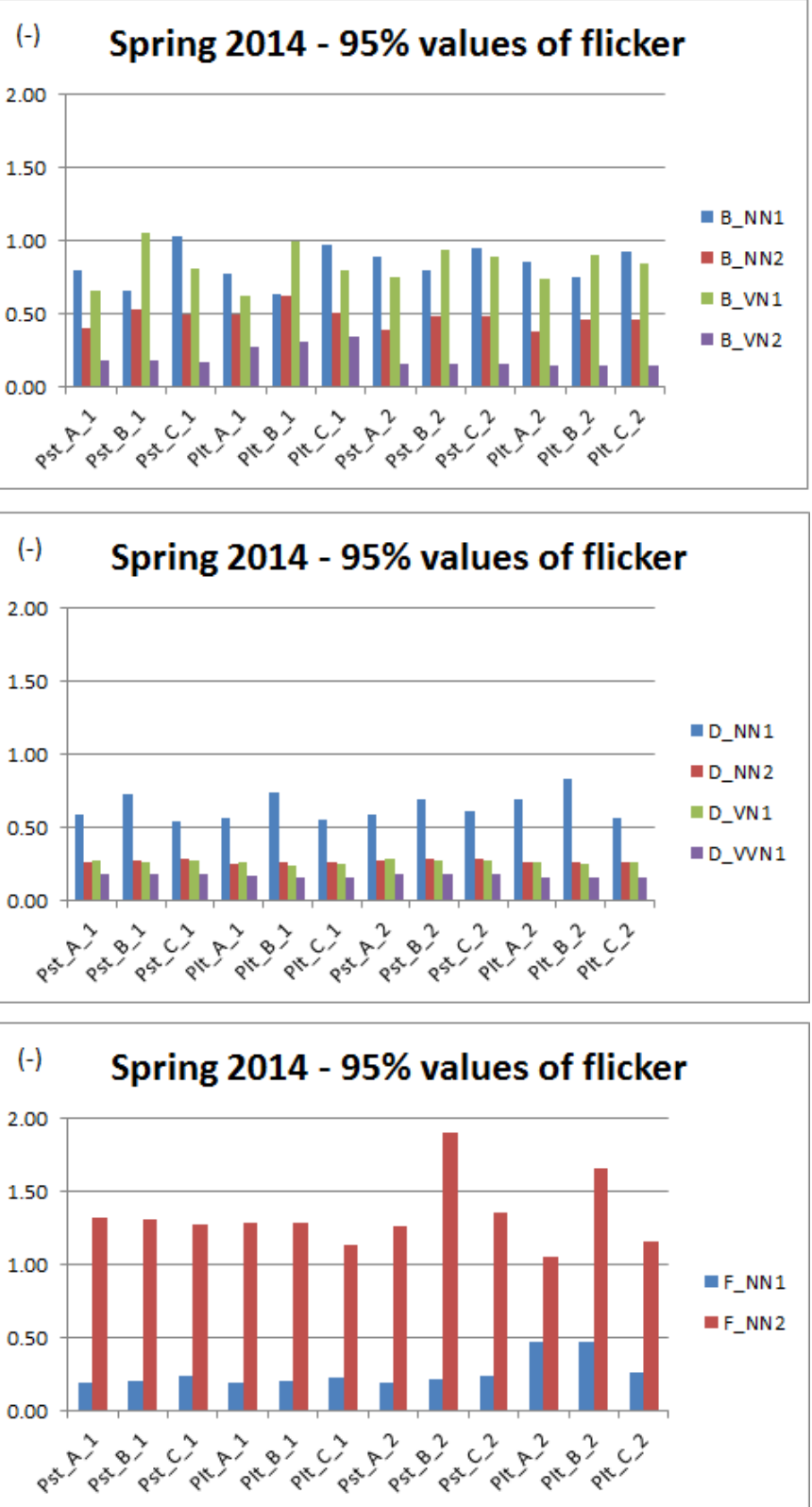

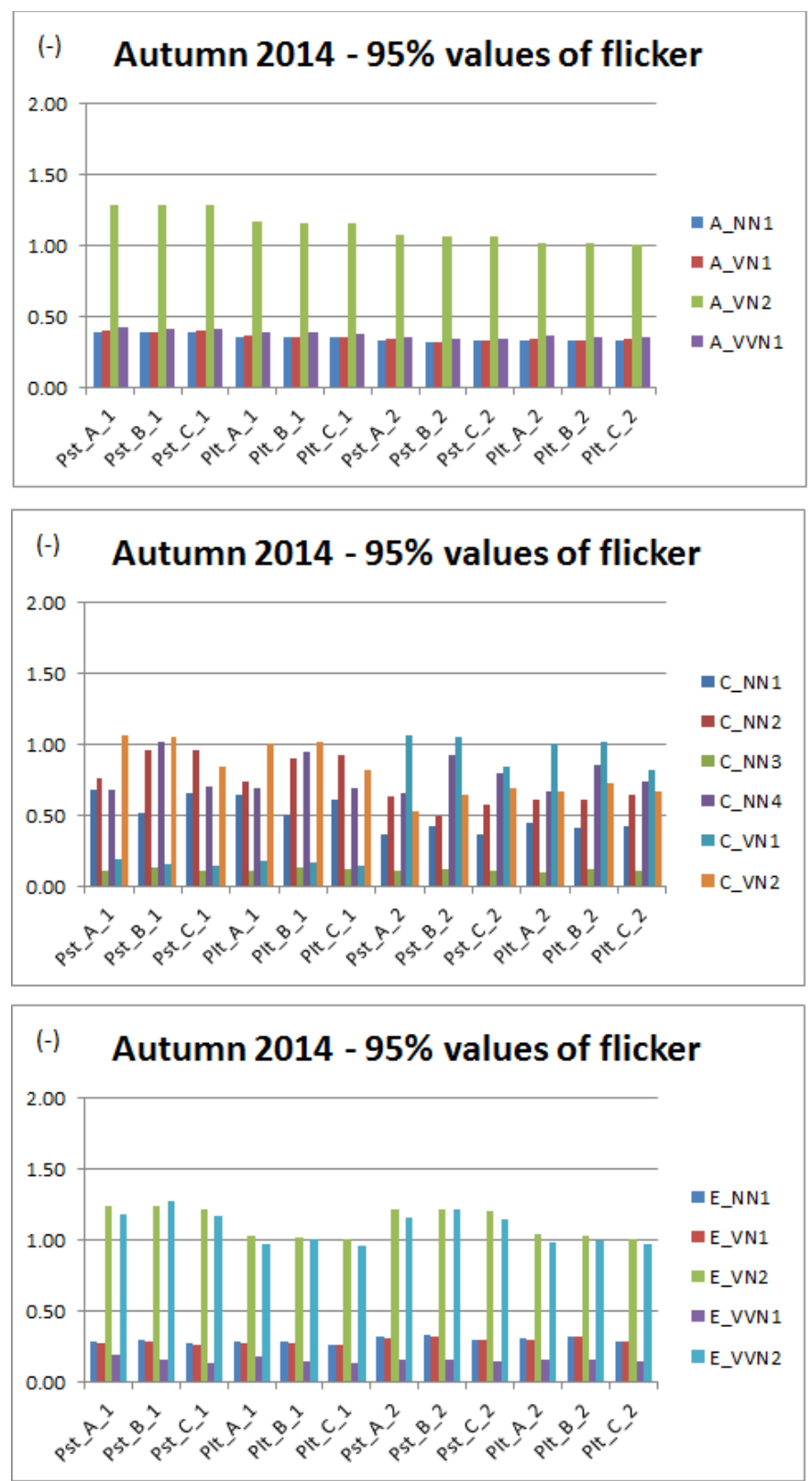

Fig. 6. The results of the measuring of flicker - Autumn 2014

\section{QUALITY PARAMETERS MONITORING AT ALL TIMES}

As of 2001, there are analysers QWave (manufactured by LEM) fitted to distribution points of $110 \mathrm{kV}$ so as it is possible to register as much information on individual parameters of voltage quality and events in the distribution system, as possible. QWave Power measures, simultaneously, all voltage quality parameters and compares it with the limit values according to the CSN EN50160 standard, and furthermore, it also renders the current analysis. QWave Light is a simplified version, evaluating only current for its all guaranteed and indicative parameters.

The rules for operation of distribution networks (DN) contain Annex 3 (Quality of electrical power in the distribution system,
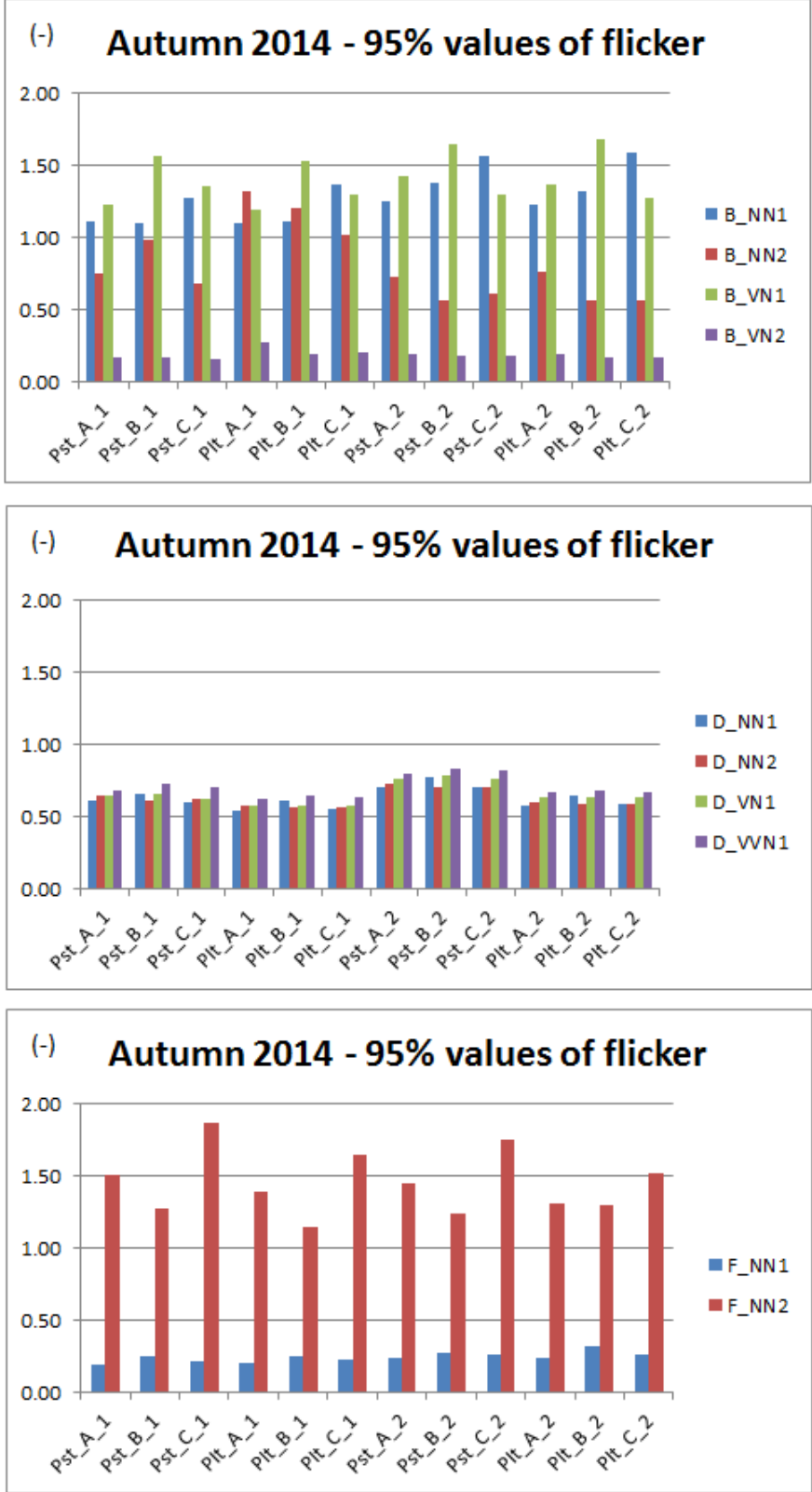

manners of determination and evaluation). Based on these rules, there must be quality analyser of the electrical power supply fitted at all times, as of January 1, 2006, for all HV supply terminals, and as of January 1, 2007, for all supplies from DN $110 \mathrm{kV}$. The data acquired by these analysers are being continuously processed and archived. Ref. [4]

On the Fig. 7 you can see the illustration of the continuously monitoring power quality parameters at the selected place OS$8 \mathrm{MV}$ distribution network. On the diagram there are also placed the results acquired by the cyclic monitoring at the same place as it was described in the previous part of the contribution. For example, you can see that the values of flicker acquired by the cyclic monitoring makes approximately one quarter of the maximal value acquired by the yearly monitoring. 

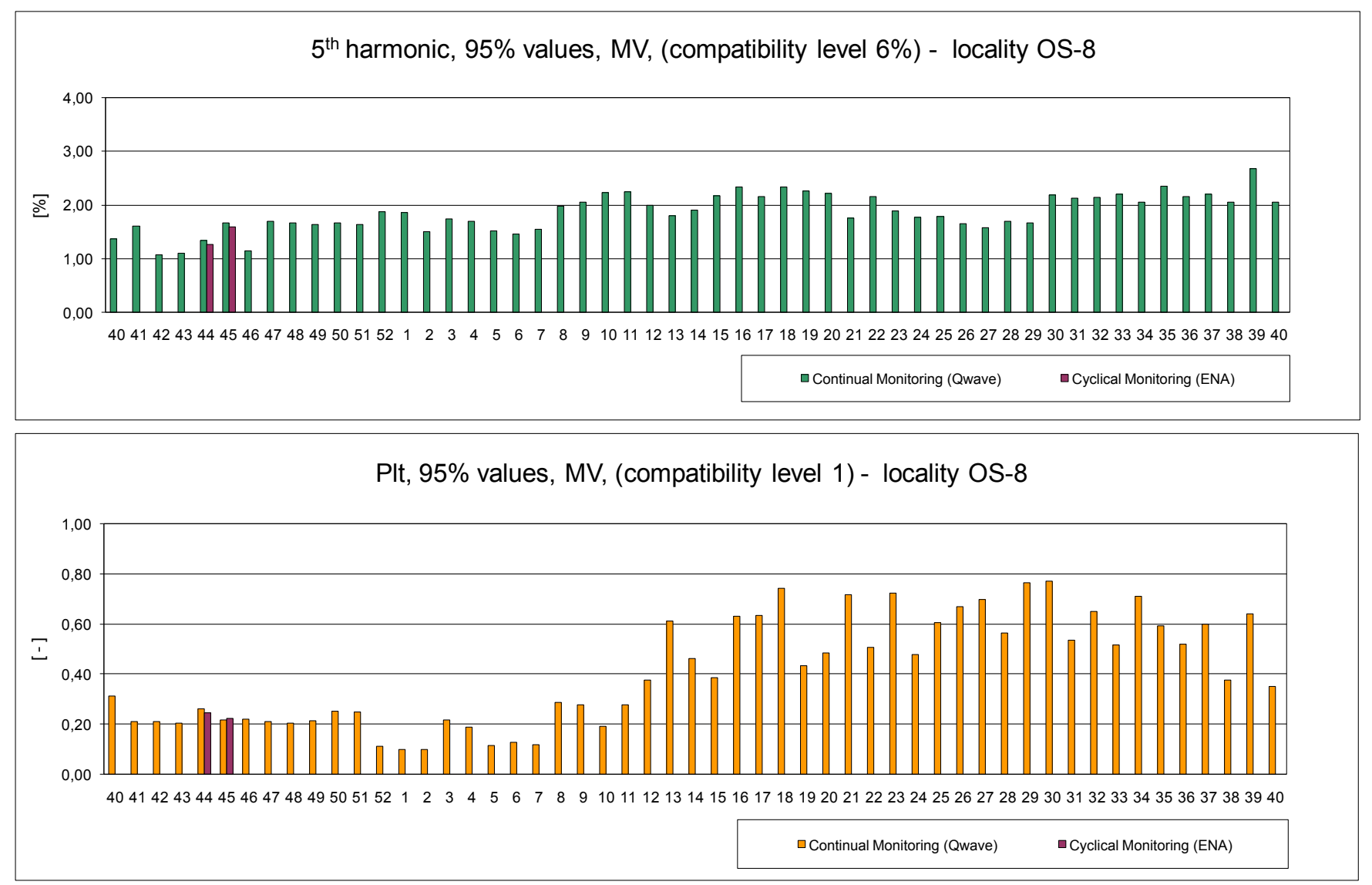

Fig. 7. $5^{\text {th }}$ harmonic and flicker $\left(\mathrm{P}_{\mathrm{lt}}\right)$ in MV network OS-8

\section{USE OF INTELLIGENT ELECTROMETERS FOR MONITORING OF QUALITY PARAMETERS}

Characteristic parameters of voltage within low and high voltage networks are introduced in the standard ČSN EN 50160. The revised normative ČSN EN 50160 further defines parameters for very-high voltage networks.

Current intelligent electrometers usually provide data that is not in compliance with the normative mentioned above, but they afford relevant data for energy companies usable in operation.

As for usage in operation of distribution, the most crucial issues are long-term monitoring of voltage deviations and their evaluation in compliance with standard ČSN EN 50160. Further important values are overvoltage, falls and short-time blackouts typically with 1s sample period (thus quite not in accordance with ČSN EN 50160). Yet this data can give a power company relevant information, because events longer than 1 second still report about the conditions of distribution network and during the changes (usually rising) they indicate the error states. Unfortunately, these data are recorded as events, but the number or logged events are limited and set low.
Harmonics and THD, even evaluated until low frequencies only (till 10th or 25th harmonic multiple), can provide relevant information. For example, when the third harmonic element rises, it can indicate the problem of power transformer. A significant rise of any harmonic or THD indicates the problem with resonances in distribution network.

\section{CONCLUSIONS}

Three PQ problems are summarised in the paper:

- the results of long-term (15 years) monitoring of selected voltage quality parameters and evaluation of trends in changes of these parameters; the most severe changes were registered for flicker;

- measurement and evaluation of the 15th and 21st voltage harmonics in the LV distribution network. The compatibility level of $0.5 \%$ was not exceeded at any measurement point;

- from the present results of the flicker monitoring it is possible to state that at some feeding points the values of Plt were more than 1 . The greatest value was 1.7. 
- the results from continuously monitoring of power quality parameters manifest that the measured values can differ during the year and therefore the continuously monitoring is wellfounded.

- current intelligent electrometers usually provide data that is not in compliance with the normative mentioned above, but they afford relevant data for energy companies usable in operation.

\section{ACKNOWLEDGMENT}

This research was partially supported by the SGS grant from VSB - Technical University of Ostrava (No. SP2016/95 and No. SP2016/146).

\section{REFERENCES}

[1] EN 50160 Ed.3:2010 "Voltage characteristics of electricity supplied by public electricity networks".

[2] P. Krejci, P. Santarius, P. Bilík, R. Čumpelík "The Periodical and Continual PQ Monitoring of Selected Distribution Networks in Czech Republic," Electrical Power Quality and Utilisation 2011, Lisabon, 2011, pp. 1-6.

[3] M. Tesarova, M. Kaspirek "Evaluation of long-term voltage dip monitoring in the distribution system," International Scientific Symposium on Electrical Power Engineering 2011, Košice, 2013, pp.268271.

[4] P. Krejci, P. Santarius, R. Hájovský, R. Velička, R. Čumpelík "Power Quality Monitoring in Selected Distribution Networks in Czech Republic," Electromagnetic Disturbances 2011, Bialystok, 2011, p. 145148 . 